Artikel Riset

DOI : 10.33751/jf.v10i1.1872
Fitofarmaka Jurnal Ilmiah Farmasi

Vol.10, No.1, Juni $2020: 32-41$

p-ISSN : 2087-9164 e-ISSN : 2622-755X

\title{
PENGARUH PEMBERIAN EKSTRAK BIJI KOPI ARABIKA (Coffea arabica L.) TERHADAP HISTOPATOLOGI LAMBUNG TIKUS PUTIH GALUR WISTAR
}

\author{
Tovani Sri ${ }^{*}$, Rani Rubiyanti ${ }^{2}$ \\ ${ }^{1,2}$ Jurusan Farmasi, Poltekkes Kemenkes Tasikmalaya, Tasikmalaya 46115, \\ West Java, Indonesia \\ *Email: tovanisri28@gmail.com
}

\begin{abstract}
ABSTRAK
Di antara seluruh kandungan yang terdapat dalam kopi, kafein paling dikenal. Kafein apabila dikonsumsi berlebihan dapat meningkatkan ketegangan otot, merangsang kerja jantung, dan meningkatkan sekresi asam lambung. Ulkus dapat terjadi pada mukosa, submukosa dan sampai lapisan muskularis dari traktus gastrointestinal berhubungan dengan asam lambung yang mengandung $\mathrm{HCl}$. Penelitian ini bertujuan untuk mengetahui pengaruh ekstrak biji kopi arabika (Coffea arabica L.) terhadap histopatologi lambung tikus putih jantan galur Wistar. Bahan uji ekstrak biji kopi arabika diperoleh dari ekstraksi biji kopi arabika yang dilakukan dengan metode Soxhlet menggunakan etanol 70\%. Hewan uji yang digunakan dalam penelitian adalah 25 ekor tikus jantan galur Wistar yang terdiri atas kelompok kontrol negatif (tidak diberi perlakuan), kontrol positif (diinduksi aspirin $30 \mathrm{mg} / \mathrm{kg}$ bb tikus) sebagai pembanding, ekstrak etanol biji kopi dosis I (0,12 g/kg bb tikus), dosis II (0,24 g/kg bb tikus), dan dosis III $(0,48 \mathrm{~g} / \mathrm{kg}$ bb tikus), dalam kurun waktu 30 hari. Hasil menunjukkan pada histopatologi tikus Wistar kelompok ekstrak etanol kopi dosis I terdapat gambaran yang serupa dengan kelompok kontrol negatif yaitu gambaran lambung normal. Histopatologi lambung tikus Wistar kelompok IV kelompok yang diberi ekstrak etanol kopi dosis II menunjukkan adanya limfosit sedikit, edema, dan dilatasi kapiler. Pemberian ekstrak etanol biji kopi dosis III menyebabkan adanya kerusakan pada lambung, perubahan histopatologi serupa seperti pada kelompok kontrol positif yang diinduksi aspirin.
\end{abstract}

Kata kunci : Aspirin, Ekstrak Biji Kopi Arabika, Histopatologi Lambung

\section{THE EFFECT OF ARABIC COFFEE (Coffea arabica L.) SEED EXTRACT ADMINISTRATION ON STOMACH HISTOPATHOLOGY OF ALBINO WISTAR RAT}

\footnotetext{
ABSTRACT

Among all the content contained in coffee, caffeine is best known. Caffeine when consumed excessively can increase muscle tension, stimulate heart work, and increase the secretion of gastric acid. Ulcers can occur in the mucosa, submucosa and until the musculoskeletal lining of the gastrointestinal tractus is associated with gastric acid that contains $\mathrm{HCl}$. This study aims to determine the influence of arabica coffee bean extract (Coffea arabica L.) against histopathology of the stomach of the white rats Wistar strain. The Arabica coffee bean extract test material is obtained from the extraction of arabica
} 
coffee beans done by Soxhlet method using ethanol 70\%. The test animal used in the study was a 25 Wistar strain rats that consisted of negative control groups (not given treatment), positive control (aspirin-induced $30 \mathrm{mg} / \mathrm{kg}$ bw rats) as a comparator, extract coffee bean ethanol dose I ( $0.12 \mathrm{~g} / \mathrm{kg}$ bw rats), Dose II ( $0.24 \mathrm{~g} / \mathrm{kg}$ bw rats $)$, and dose III $(0.48 \mathrm{~g} / \mathrm{kg}$ bw rats), within 30 days. Results showed on rats histopathology which is given ethanol coffee extract dose I there is a similar picture to the negative control group i.e. the normal gastric picture. Histopathology of rat Gastric Wistar Group IV given ethanol coffee extract dose II indicates the presence of slight lymphocytes, edema, and capillary dilation. The administration of coffee bean ethanol extract dose III caused the presence of damage to the stomach, similar histopathology changes in the aspirininduced positive control group.

Keywords: Arabica Coffee Bean Extract, Aspirin, Gastric Histopathology

\section{PENDAHULUAN}

Kopi adalah minuman yang paling populer di dunia setelah air (George et al., 2008). Di antara seluruh kandungan yang terdapat dalam kopi, kafein paling dikenal. Namun cafestol, kahweol dan asam chlorogenat, merupakan senyawa yang terdapat dalam kopi dengan sifat antioksidan (Higdon et al, 2006). Selain memiliki citarasa yang khas, kopi memiliki manfaat sebagai antioksidan karena memiliki polifenol dan merangsang kinerja otak (Mulato, 2001). Data dari penelitian lain pada hewan menunjukkan bahwa kafein (Shi, 1997), tetapi sebagian besar asam klorogenat dan turunannya (Arion et al., 1997; Clifford, 2000; Ong and B.Tan, 2012.; Hunyadi et al., 2012) memiliki efek hipoglikemik dengan mekanisme yang berbeda. Masalah utama dari pengkonsumsian kopi adalah kadar kafein yang terkandung dalam kopi (Mulato, 2001). Kopi robusta memiliki kandungan kafein hampir dua kali lebih besar, yaitu sebesar 2,4\% dibanding dengan kopi arabika yaitu sebesar $1,3 \%$ dalam kondisi kering (Weinberg, 2001). Di wilayah Tasikmalaya kopi arabika yang berasal dari genus Coffea, family Rubiaceae (Davies et al., 2006; Castilla, 2012) lebih banyak diproduksi dibandingkan dengan kopi robusta alasannya karena harga jual arabika yang jauh lebih tinggi dibanding dengan kopi robusta.

Kopi diketahui merangsang lambung untuk memproduksi asam lambung sehingga menciptakan lingkungan yang lebih asam dan dapat mengiritasi mukosa lambung (Rahma, dkk. 2013). Kafein di dalam kopi dapat mempercepat proses terbentuknya asam lambung. Hal ini membuat produksi gas dalam lambung berlebih sehingga sering mengeluhkan sensasi kembung di perut. Bila mukosa lambung rusak, maka terjadi difusi $\mathrm{HCl}$ ke mukosa lambung dan $\mathrm{HCl}$ akan merusak mukosa. Kehadiran $\mathrm{HCl}$ di mukosa lambung menstimulasi perubahan pepsinogen menjadi pepsin. Pepsin merangsang pelepasan histamin dari sel mast. Histamin akan menyebabkan peningkatan permeabilitas kapiler sehingga terjadi perpindahan cairan dari intrasel ke ekstrasel dan menyebabkan edema dan kerusakan kapiler sehingga timbul perdarahan pada lambung (Mawey et al, 2014; Rizkianil, 2009).

Jika lambung sering terpapar dengan zat iritan,seperti kopi maka inflamasi akan terjadi terus-menerus. Jaringan yang meradang akan diisi oleh jaringan fibrin sehingga lapisan mukosa lambung dapat hilang dan terjadi atropi sel mukosa lambung (Angkow et al, 2014). Selain itu, apabila kafein 
dikonsumsi berlebihan dapat merangsang kerja jantung, dan meningkatkan sekresi asam lambung (Mulato, 2001).

Pada penelitian sebelumnya, telah dilakukan pemeriksaan kadar kafein di tiga daerah Jawa Barat, yaitu Garut, Pangalengan dan Tasikmalaya. Diperoleh kadar kafein daerah Pengalengan 1,16\%; Tasikmalaya $2,70 \%$ dan Garut $1,38 \%$ (Rubiyanti, 2015). Kadar kafein tertinggi berasal dari kota Tasikmalaya yang diperoleh dari daerah Cigalontang.

Aspirin (asam asetil salisilat) adalah analgesik, anti piretik, dan antiinflamasi yang luas digunakan dan digolongkan dalam obat bebas. Pemberian aspirin dapat menimbulkan perubahan perubahan kualitatif mukus lambung sehingga mengakibatkan kerusakan jaringan terutama pembuluh darah. Aspirin digunakan sebagai penginduksi dalam kelompok kontrol positif (J. N., et al, 2013).

Berdasarkan uraian di atas, dilakukan penelitian dengan tujuan mengetahui pengaruh ekstrak biji kopi arabica (Coffea arabica L.) terhadap perubahan histopatologi lambung pada tikus putih (Rattus norvegicus) strain Wistar Jantan.

\section{METODE PENELITIAN Alat dan Bahan}

Gelas beaker, batang pengaduk, grinder, vorteks, kertas saring, ayakan 200 mesh, aluminium foil, rotary evaporator, timbangan analitik, alat penggiling, corong pisah, botol kecil, hot plate, sonikator, kulkas pendingin dan cawan petri, wadah makanan tikus, botol minuman tikus, kawat kasa dan dadak padi, sonde lambung metal, gunting, sarung tangan disposable, tempat otopsi, jarum, gunting, pinset, pisau bedah, toples, krus silikat, tanur, oven, vial dan tutup, spatula, pipet tetes, kertas timbang, mikropipet, kertas saring, rak tabung reaksi, sonde oral tikus, dan alat-alat gelas yang biasa digunakan.

Biji kopi arabika (Coffea arabica L.) diperoleh dari Cigalontang Tasikmalaya, etanol 70\%, etanol $96 \%$, CMC, makanan hewan (pellet), serbuk magnesium, amil alkohol, asam klorida, natrium hidroksida, besi (III) klorida, pereaksi Steasny, natrium asetat, amonia, kloroform, pereaksi Dragendorff, pereaksi Mayer, eter, pereaksi Liebermann Burchard, air suling (aquadest), pembanding kafein, bahan pewarna Harris-Hematoxylin Eosin.

\section{Penyiapan Bahan dan Simplisia}

Bahan tanaman dideterminasi. Hasil dari determinasi yang telah dilakukan menunjukkan bahwa biji kopi arabika ini terrmasuk ke dalam spesies Coffea arabica $\mathrm{L}$.

Biji kopi arabika dikumpulkan dan disortasi basah untuk memisahkan kotoran dan bahan-bahan asing dari biji. Biji kopi disikat di bawah air mengalir, ditiriskan.

Sebelum diekstraksi, biji kopi arabika disangrai dengan mesin sangrai kopi berbobot $5 \mathrm{~kg}$ dengan kontrol suhu $210{ }^{\circ} \mathrm{C}$ selama 8 menit. Setelah disangrai, biji kopi arabika dihaluskan dengan menggunakan mesin grinder sehingga diperoleh serbuk simplisia halus dengan ukuran setara dengan mesh 60 .

\section{Pembuatan Ekstrak Biji Kopi Arabika}

Ekstraksi $640 \mathrm{~g}$ simplisia dengan metode Soxhlet dengan pelarut etanol $70 \%$ hingga ekstraksi sempurna. Seluruh ekstrak cair yang diperoleh dipekatkan oleh rotary evaporator pada suhu 40-50 ${ }^{\circ} \mathrm{C}$ dan dilanjutkan dengan penguapan kembali di atas penangas air pada suhu 40 
${ }^{\circ} \mathrm{C}$ hingga diperoleh berat ekstrak konstan. Seluruh ekstrak akhir yang diperoleh ditimbang dan dihitung rendemen ektrak (Depkes RI, 1986). Pada ekstrak kering dilakukan karakterisasi melalui penetapan kadar sari larut air, kadar sari larut etanol, susut pengeringan, kadar abu total (Depkes RI, 2000), bobot jenis larutan ekstrak $1 \%$, dan penapisan fitokimia (Depkes RI, 2000). Juga dilakukan penetapan kadar kafein dalam ekstrak menggunakan spektrofotometer Uv-Vis.

\section{Pembuatan Suspensi CMC 1\%}

Suspensi CMC 1\% dibuat dengan melarutkan 1 g CMC ke dalam $30 \mathrm{~mL}$ aquadest dipanaskan sambil diaduk sampai homogen. Kemudian ditambahkan dengan aquadest sampai volume $100 \mathrm{~mL}$, lalu didinginkan.

\section{Pembuatan Larutan Ekstrak Biji Kopi Arabika}

Dibuat ekstrak etanol biji kopi dosis I $(0,12 \mathrm{~g} / \mathrm{kg}$ bb tikus), ekstrak etanol biji kopi dosis II ( $0,24 \mathrm{~g} / \mathrm{kg}$ bb tikus), ekstrak etanol biji kopi dosis III $(0,48 \mathrm{~g} / \mathrm{kg}$ bb tikus). Ekstrak biji kopi arabika kental ditimbang sesuai dengan dosis untuk volume $100 \mathrm{~mL}$ kemudian disuspensikan dengan larutan CMC dalam labu ukur 100 $\mathrm{mL}$.

\section{Persiapan Hewan Uji}

Sampel diambil secara acak dari populasi dengan metode simple random sampling. Kriteria inklusi sampel penelitian antara lain tikus putih jantan (Rattus norvegicus) jantan dewasa galur Wistar, usia 3-4 bulan, kondisi fisik sehat dan tidak tampak cacat secara anatomi. Kriteria eksklusi sampel penelitian antara lain tikus tampak sakit sebelum perlakuan dan terdapat kelainan anatomi. Hewan uji diadaptasikan selama seminggu sebelum perlakuan. Uji etik terhadap kelayakan penelitian telah dilakukan dengan sertifikat persetujuan etik dengan KEPPKN Registration Number: 3278012P yang dikeluarkan Komisi Etik Penelitian Kesehatan (KEPK) Poltekkes Kemenkes Tasikmalaya.

\section{Perlakuan}

Pada penelitian ini dilakukan perlakuan selama 30 hari, masing-masing bahan uji diberikan secara oral kepada 5 hewan uji pada 5 kelompok terdiri atas kelompok I adalah kontrol negatif yang tidak diberi perlakuan, kelompok II yaitu sebagai kontrol positif yang diinduksi aspirin $30 \mathrm{mg} / \mathrm{kg}$ bb tikus agar sakit gastritis sebagai pembanding, kelompok III yaitu ekstrak etanol biji kopi dosis I ( $0,12 \mathrm{~g} / \mathrm{kg}$ bb tikus), kelompok IV yaitu ekstrak etanol biji kopi dosis II $(0,24 \mathrm{~g} / \mathrm{kg}$ bb tikus), kelompok $\mathrm{V}$ yaitu ekstrak etanol biji kopi dosis III $(0,48 \mathrm{~g} / \mathrm{kg}$ bb tikus), yang diberikan secara oral.

\section{Pembedahan}

Dilakukan euthanasia pada tikus dengan inhalasi $\mathrm{CO}_{2}$ (AVMA Guidelines for the Euthanasia of Animals, 2013). Selanjutnya bagian perut bawah tikus dibelah hingga bagian dada. Berikutnya membelah bagian perut bawah tikus hingga bagian dada, kemudian organ dikeluarkan dari dalam tubuh tikus. Organ lambung harus dipisahkan dari bagian usus, hati, dan empedu yang melekat.

\section{Pengamatan Mikroskopik}

Setelah tikus mati, dilakukan laparotomi untuk mengambil lambung tikus untuk preparat mikroskopis. Pembuatan preparat mikroskopis dilakukan dengan metode parafin dengan pewarnaan Harris-Hematoxylin Eosin (HE). 


\section{HASIL DAN PEMBAHASAN Penyiapan Simplisia}

Kopi arabika Cigalontang yang digunakan dalam penelitian ini berasal dari biji kopi arabika yang ditanam dan dipanen langsung di desa Cigalontang, Kabupaten Tasikmalaya, Jawa Barat. Tujuan dari menghaluskan biji kopi arabika ini adalah untuk memperkecil ukuran partikel sehingga kontak simplisia biji kopi dengan pelarut bisa lebih besar, hal ini berdampak pada proses penarikan senyawa yang dapat menjadi lebih mudah dan lebih banyak.

\section{Pembuatan Ekstrak Biji Kopi Arabika}

Ekstraksi dilakukan untuk menarik seluruh komponen senyawa dalam tanaman. Ekstraksi seluruh simplisia dengan metode Soxhlet dengan pelarut etanol $70 \%$ hingga ekstraksi sempurna.
Pemilihan etanol sebagai pelarut dikarenakan etanol merupakan pelarut yang paling sesuai pada ekstraksi kafein, karena kafein lebih banyak terekstrak ke dalam etanol dibandingkan pelarut lainnya seperti dietil eter, karbon tetraklorida, dan n-heksana. Kafein merupakan alkaloid, maka dengan penambahan etanol akan memudahkan pelarutan kafein, selain itu beberapa pertimbangan seperti harga, dan kelarutan, maka etanol lebih aman dan murah untuk digunakan, selain karena memiliki titik didih yang rendah. Setelah proses ekstraksi, seluruh ekstrak akhir yang diperoleh ditimbang dan dihitung rendemennya. Rendemen ekstrak yang diperoleh sebanyak 13,95\%. Hasil pemeriksaan karakteristik simplisia ditampilkan pada Tabel 1.

Tabel 1. Hasil Karakteristik Simplisia

\begin{tabular}{lc}
\hline Karakteristik Simplisia & Hasil \\
\hline Kadar Sari Larut Air $(\% \mathrm{~b} / \mathrm{b})$ & 1,21 \\
Kadar Sari Larut Etanol $(\% \mathrm{~b} / \mathrm{b})$ & 0,86 \\
Kadar Abu Total $(\% \mathrm{~b} / \mathrm{b})$ & 7,78 \\
\hline
\end{tabular}

Berdasarkan tabel di atas dapat diketahui bahwa simplisia kopi arabika lebih banyak yang tersari dalam air dibanding dalam etanol. Hasil pemeriksaan karakteristik ekstrak dapat dilihat pada Tabel 2.

Tabel 2. Hasil Karakteristik Ekstrak

\begin{tabular}{lc}
\hline \multicolumn{1}{c}{ Karakteristik Ekstrak } & Hasil \\
\hline Kadar Sari Larut Air $(\% \mathrm{~b} / \mathrm{b})$ & $4,60 \pm 0,27$ \\
Kadar Sari Larut Etanol $(\% \mathrm{~b} / \mathrm{b})$ & $4,17 \pm 0,53$ \\
Kadar Abu Total $\%$ b/b) & 10,0 \\
Bobot Jenis Larutan 1\% $(\mathrm{g} / \mathrm{mL})$ & 1,004 \\
Bobot Jenis Larutan 5\% $(\mathrm{g} / \mathrm{mL})$ & 1,014 \\
\hline
\end{tabular}

Hasil pemeriksaan kandungan kimia menunjukkan baik simplisia kopi maupun ekstrak etanol kopi mengandung golongan senyawa flavonoid, alkaloid, kuinon, dan polifenol. 
Tabel 3. Penapisan Fitokimia Ekstrak

\begin{tabular}{lcc}
\hline \multirow{2}{*}{ Golongan Senyawa } & \multicolumn{2}{c}{ Bahan Uji } \\
\cline { 2 - 3 } & Simplisia kopi & $\begin{array}{c}\text { Ekstrak } \\
\text { Etanol kopi }\end{array}$ \\
\hline Flavonoid & + & + \\
Saponin & - & - \\
Kuinon & + & + \\
Tanin & - & - \\
Alkaloid & + & + \\
Polifenol & + & + \\
\hline
\end{tabular}

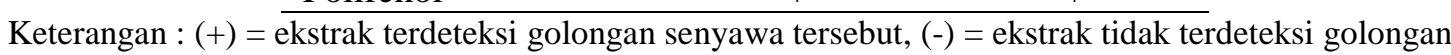
senyawa tersebut

Hasil penelitian menunjukkan baik simplisia maupun ekstrak etanol biji kopi mengandung senyawa polifenol. Daun, buah dan akar Coffea arabica mengandung saponin, flavonoida, dan polifenol, buah dan bijinya mengandung alkaloida (Spiller, 1998). Kopi mempunyai manfaat sebagai antioksidan karena memiliki senyawa polifenol yang dapat merangsang kinerja otak (Mulato, 2001), dapat menurunkan prevalensi diabetes melitus tipe 2 (Van Dam and Feskens, 2002;. Isogawa et al., 2003; Salazar-Martinez et al, 2004), mempunyai efek hipoglikemik (Shi, 1997; Arion et al., 1997; Clifford, 2000; Ong and B.Tan, 2012.; Hunyadi et al., 2012) dan mempunyai efek antidiabetes (Julio Campos et al.,2013).

Pada penetapan kadar kafein, terlebih dahulu dilakukan penentuan panjang gelombang maksimum. Panjang gelombang maksimum yang diperoleh yaitu $275 \mathrm{~nm}$. Setelah panjang gelombang maksimum ditentukan selanjutnya dibuat kurva kalibrasi yang diperoleh dengan cara membuat seri konsentrasi $4,6,8$, 10,dan $12 \mathrm{ppm}$ yang dibaca serapannya pada panjang gelombang maksimum. Persamaan kurva kalibrasi merupakan hubungan yang linier antara sumbu $x$ dan sumbu $\mathrm{y}$ dimana sumbu $\mathrm{x}$ dinyatakan dengan konsentrasi yang diperoleh, sedangkan sumbu y merupakan absorbansi atau serapan yang diperoleh dari hasil pengukuran (Uno, 2015). Penentuan linieritas kafein dalam pelarut etanol dengan konsentrasi 4, 6, 8, 10,dan $12 \mathrm{ppm}$ pada panjang gelombang $275 \mathrm{~nm}$ dapat dilihat sebagai berikut :

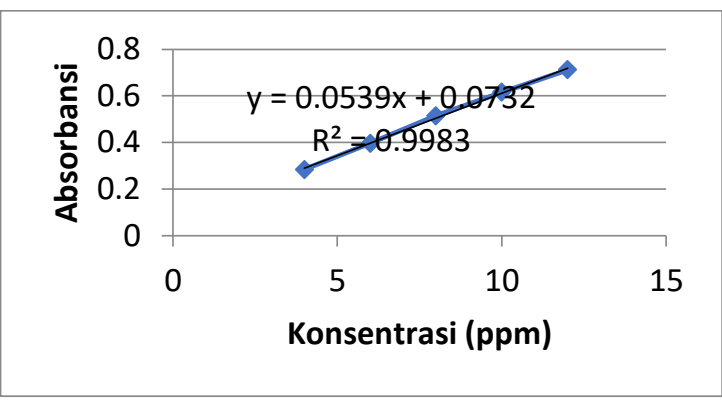

Gambar 1. Kurva kalibrasi larutan kafein baku standar

Berdasarkan kurva kalibrasi standar tersebut diperoleh hubungan yang linier antara konsentrasi dan absorbansi dengan nilai koefisien korelasi $r=0,999$, nilai $\mathrm{r}^{2}=0,9983$, dan persamaan regresi linier $\mathrm{y}=0,0539 \mathrm{x}+0,0732$. Harga koefisien $\mathrm{r}$ yang mendekati 1 menyatakan hubungan linear antara konsentrasi dengan serapan yang dihasilkan (Uno, 2015). Dengan kata lain kurva kalibrasi yang dihasilkan ini memenuhi hukum 
Lambert-Beer yang berbunyi bahwa serapan berbanding lurus terhadap konsentrasi dan ketebalan sel (Dewi, 2019). Koefisien korelasi yang dihasilkan sesuai dengan kriteria penerimaan koefisien korelasi (r) yang baik menurut Shargel (2005) yaitu $r \geq 0,95$. Penetapan kadar kafein dilakukan dengan menggunakan spektrofotometer Uv-Vis.
Sampel ditimbang sebanyak $0,1 \mathrm{~g}$ kemudian dilarutkan ke dalam $100 \mathrm{~mL}$ etanol. Kemudian diambil 2,5 mL larutan sampel dan dimasukkan ke dalam labu ukur 100 mL kemudian tambahkan etanol hingga batas. Pengenceran ini bertujuan agar larutan sampel tidak terlalu pekat pada saat diuji serapannya.

Tabel 4. Absorbansi dan Kadar Kafein pada Ekstrak Etanol Biji Kopi Arabika

\begin{tabular}{cccc}
\hline $\begin{array}{c}\text { Jenis } \\
\text { sampel }\end{array}$ & $\begin{array}{c}\text { Absorbansi } \\
(\mathrm{y})\end{array}$ & $\begin{array}{c}\text { Konsentrasi (x) } \\
(\mathrm{ppm})\end{array}$ & $\begin{array}{c}\text { Kadar kafein } \\
\text { dalam 1 g } \\
\text { ekstrak }\end{array}$ \\
\hline $\begin{array}{c}\text { Ekstrak } \\
\text { etanol } \\
\text { kopi }\end{array}$ & 0,729 & 12,17 & $2,434 \%$ \\
\hline
\end{tabular}

Jumlah kafein dalam ekstraksi kopi dapat dipengaruhi oleh beberapa faktor, di antaranya yaitu suhu pemanggangan, ukuran partikel pada saat grinding, metode ekstraksi, suhu ekstraksi, dan waktu pada saat ekstraksi (M.D., Ayu , 2019).

Pada uji pengaruh pemberian ekstrak terhadap tikus, hasil menunjukkan bahwa pada lambung tikus kelompok I kontrol negatif terlihat adanya lapisan mukosa (skala pembesaran 100x).

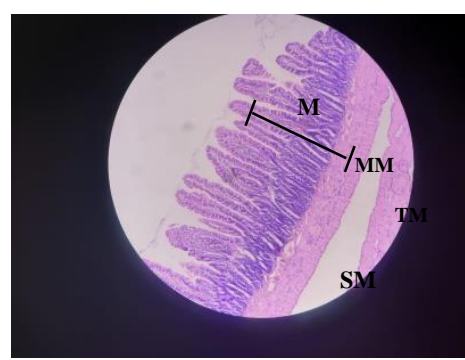

Gambar 2. Gambaran mikroskopik lambung tikus Wistar kelompok kontrol negatif. Pembesaran 100x. Histologi lambung tikus bagian pilorus. $\mathrm{M}=$ mukosa; $\mathrm{MM}=$ muskularis mukosa; $\mathrm{SM}=$ submukosa; $\mathrm{TM}=$ tunika muskularis
Tikus Wistar kelompok II merupakan kelompok kontrol positif yaitu hewan yang diinduksi oleh aspirin sebagai pembanding. Menurut literatur, aspirin dapat menyebabkan kerusakan pada lambung. Tampak pada gambar lambung terdapat limfosit, eosinofil, edema, pelebaran vaskular.

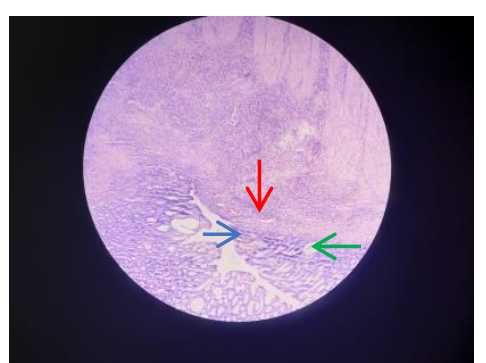

Gambar 3. Gambaran mikroskopik lambung tikus Wistar kelompok kontrol positif menggunakan aspirin. Pembesaran 100x. Terlihat adanya vasodilatasi (panah merah). edema (panah biru), limfosit (panah hijau)

Tikus Wistar kelompok III merupakan kelompok yang diberi ekstrak etanol kopi dosis I $(0,12 \mathrm{~g} / \mathrm{kg}$ bb tikus $)$ menunjukkan gambaran yang serupa dengan kelompok kontrol negatif yaitu 
gambaran lambung normal. Tidak terdapat edema dan pelebaran vaskular.

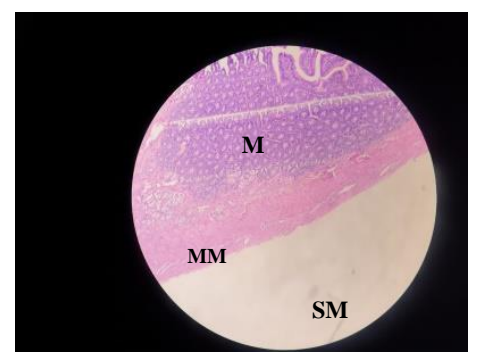

Gambar 4. Gambaran mikroskopik lambung tikus Wistar kelompok III yaitu kelompok uji dosis I. Pembesaran 100x. $\mathrm{M}=$ mukosa; $\mathrm{MM}=$ muskularis mukosa; $\mathrm{SM}=$ submukosa

Tikus Wistar kelompok IV merupakan kelompok yang diberi ekstrak etanol kopi dosis II $(0,24 \mathrm{~g} / \mathrm{kg}$ bb tikus $)$ menunjukkan adanya limfosit sedikit, edema, dan dilatasi kapiler. Pada kelompok dosis II derajat edema lebih ringan dibanding dosis III, limfosit berkurang tapi masih ada, dan pelebaran pembuluh darah. Hasil menunjukkan bahwa gambaran mikroskopik kelompok IV yang diberi ekstrak etanol kopi dosis II memberikan pengaruh kerusakan pada lambung yang terlihat pada gambar mikroskopik.

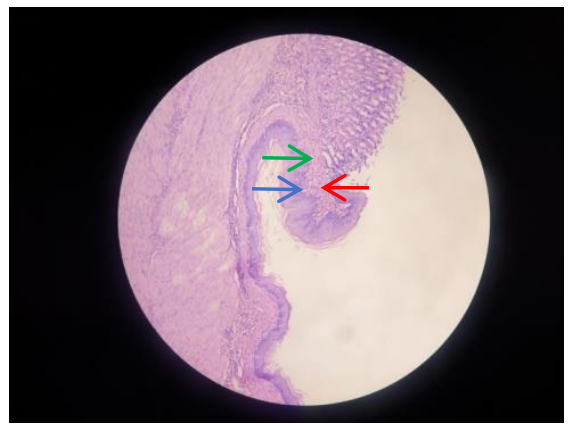

Gambar 5. Gambaran mikroskopik lambung tikus Wistar kelompok IV yaitu kelompok uji dosis II. Pembesaran 100x. Terlihat adanya vasodilatasi (panah merah), edema (panah biru), limfosit (panah hijau)
Tikus Wistar kelompok V merupakan kelompok yang diberi ekstrak etanol kopi dosis III $(0,48 \mathrm{~g} / \mathrm{kg}$ bb tikus) menunjukkan gambaran yang sama dengan kontrol positif yang diberi aspirin. Pada gambaran mikroskopik terdapat pelebaran pembuluh darah yang ditandai oleh warna merah dengan udem ditandai warna putih.

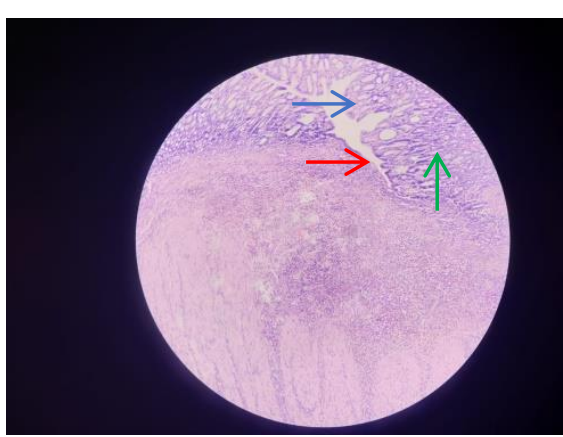

Gambar 6. Gambaran mikroskopik lambung tikus Wistar kelompok V yaitu kelompok uji dosis III. Pembesaran 100x. Terlihat adanya vasodilatasi (panah merah), edema (panah biru), limfosit (panah hijau)

Hasil menunjukkan bahwa gambaran pada kelompok $\mathrm{V}$ yaitu kelompok dosis III terdapat perubahan histopatologi yaitu pelebaran pembuluh darah dan udem.

\section{KESIMPULAN}

Pemberian ekstrak biji kopi Arabica (Coffea arabica L.) dapat menyebabkan perubahan pada histopatologi lambung pada tikus putih jantan (Rattus norvegicus) galur Wistar.

Perubahan pada histopatologi lambung tikus putih jantan (Rattus norvegicus) galur Wistar secara mikroskopik dengan pemberian ekstrak biji kopi Arabica (Coffea arabica L.) dosis III $(0,48 \quad \mathrm{~g} / \mathrm{kg} \quad \mathrm{bb}$ tikus $)$ menunjukkan adanya kerusakan pada lambung, gambaran yang serupa dengan tikus yang diinduksi aspirin. 


\section{REFERENSI}

Angkow J, Robot F, Onibala F. 2014. Faktor-faktor yang Berhubungan dengan Kejadian Gastritis di Wilayah Kerja Puskesmas Bahu kota manado. Manado. Universitas Sam Ratulangi.

Arion, W. J., W. K. Canfield, F. C. Ramos, P. W.Schindler, H. J. Burger, H. Hemmerle, G.Schubert, P. Below and A. W. Herling. 1997. Chlorogenic acid and hydroxyl nitrobenzaldehyde: new inhibitors of hepatic glucose 6-phosphatase. Arch. Biochem. Biophys. 339(2):315-322.

Davies, A., R. Govaerts, D. Bridson and P.Stoffelen. 2006. An annotated taxonomic conspectus of the genus Coffea (Rubiaceae).Bot. J. Linn. Soc. 152:465-512.

AVMA Guidelines for the Euthanasia of Animal. 2013.

Castilla, Y. 2012. Conservació $n$ de recursos fitogenéticos de cafeto (Coffea spp.) por métodos biotecnoló gicos: Una alternativa parasu preservació n. Cultivos Tropicales. 33(4):29-39.

Clifford, M. 2000. Chlorogenic acid and other cinnamates-nature, occurence, dietary burden, absorption and metabolism. J. Sci. Food Agric. 80:33-43.

Departemen Kesehatan Republik Indonesia.. 1986. Sediaan Galenik. Jakarta: George, S., K. Ramalakshmi and R. Mohan. 2008. A perception on health benefits of coffee. Crit. Rev. Food Sci. Nutr. 48:464-486.

Dewi, A. M. 2019. Analisis Kadar Kafein Kopi Arabika (Coffea arabica) Dengan Variasi Suhu Refluks Menggunakan Spektrofotometri
Uv-Vis. Karya Tulis Ilmiah. Tasikmalaya.

Higdon, J. and B. Frei. 2006. Coffee and health: A review of recent Humen Research. Crit. Rev. Food Sci. Nutr. 46:101-23.

Hunyadi, A., A. Martins, T. Hsieh, A. Seres and I. Zupko. 2012. Chlorogenicacid and rutin play a major role in the in vivo antidiabetic activity of Morusalba leaf extract on type ii diabetic rats. PLoS ONE 7(11): e50619. doi:10.1371/journal.pone.0050619.

Isogawa, A., M. Noda, Y. Takahashi, T. Kadowaki and S. Tsugane. 2003. Coffee consumption and risk of type 2 diabetes mellitus. Lancet 361:703-704.

Julio Campos-Florián1, Jessica BardalesValdivia, Liliana CaruajulcaGuevara and Deisy Cueva-Llanos. 2013. Anti-diabetic effect of Coffea arabica, in alloxan-induced diabetic rats. Emir. J. Food Agric. 25 (10): 772-777.

Mawey BK, Kaawoan A, Bidjuni H. 2014. Hubungan Kebiasaan Makan dengan Pencegahan Gastritis pada Siswa Kelas X di SMA Negeri 1 Likupang [Jurnal]. Manado. Universitas Sam Ratulangi.

Mishra, M. and K. Slater. 2012. Recent advances in the genetic transformation of Coffee. Biotech. Res. Internat. Article ID 580857, p. 17.

Mulato, S. 2001. Pelarutan Kafein Biji Robusta Dengan Kolom Tetap Menggunakan Pelarut Air. Jakarta: Pelita Perkebunan.

Ong, K., A. Hsu and B. Tan. 2012. Chlorogenic acid stimulates glucose transport in skeletal muscle via AMPK activation: A contributor 
to the beneficial effects of Coffee on diabetes. PLoS ONE 7(3): e32718. doi:10.1371/journal.pone.0032718.

Rahma M, Ansar J, Rismayanti. 2013. Faktor risiko kejadian gastritis di wilayah kerja Puskesmas kampili kabupaten gowa [Jurnal]. Makassar. Universitas Hasanudin

Rizkianil. 2009. Pengaruh pemberian kopi dosis bertingkat selama 30 hari terhadap gambaran histologi lambung tikus wistar [Jurnal]. Semarang. Universitas Diponegoro.

Rubiyanti, R. 2015. Penetapan Parameter Standar Simplisia Dan Ekstrak Biji Kopi Arabika (Coffea arabica L.) [Skripsi]. Bandung, Universitas Padjadjaran.

Salazar-Martínez, E., Willett, W.C, Ascherio, A., Manson, J. E., Leitzmann, M.F., Stampfer, M.J. and Hu. F.B. 2004. Coffee consumption and risk fortype 2 diabetes mellitus. Ann. Internal Med.140(1):1-8.

Shi, C. 1997. Effects of caffeine and acetylcholine on glucose-stimulated insulin release from islet transplants in mice. Cell. Transplant. 6:33-37.

Spiller, G. A. 1998. Caffeine. USA: CRC Press.

Van Dam, R. and E. Feskens. 2002. Coffee consumption and risk of type 2 diabetes mellitus. Lancet 360:1.477-1.478.

Weinberg, Bennett alan. 2001. The Word Of Caffeine. The Scientist and Culture of The Word's Most Popular Drug. Routledge: New York. 